\title{
Determination of octanol-air partition coefficients and supercooled liquid vapor pressures of PAHs as a function of temperature: Application to gas-particle partitioning in an urban atmosphere
}

\author{
Mustafa Odabasi ${ }^{\mathrm{a}, *}$, Eylem Cetin ${ }^{\mathrm{a}}$, Aysun Sofuoglu ${ }^{\mathrm{b}}$ \\ ${ }^{a}$ Faculty of Engineering, Department of Environmental Engineering, Dokuz Eylul University, Kaynaklar Campus, 35160 Buca, Izmir, Turkey \\ ${ }^{\mathrm{b}}$ Faculty of Engineering, Department of Chemical Engineering, Izmir Institute of Technology, 35460 Gulbahce-Urla, Izmir, Turkey
}

Received 3 March 2006; received in revised form 15 May 2006; accepted 18 May 2006

\begin{abstract}
Octanol-air partition coefficients $\left(K_{\mathrm{OA}}\right)$ for 14 polycyclic aromatic hydrocarbons (PAHs) were determined as a function of temperature using the gas chromatographic retention time method. $\log K_{\mathrm{OA}}$ values at $25^{\circ}$ ranged over six orders of magnitude, between 6.34 (acenaphthylene) and 12.59 (dibenz $[a, h]$ anthracene). The determined $K_{\mathrm{OA}}$ values were within factor of 0.7 (dibenz $[a, h]$ anthracene) to 15.1 (benz $[a]$ anthracene) of values calculated as the ratio of octanol-water partition coefficient to dimensionless Henry's law constant. Supercooled liquid vapor pressures $\left(P_{\mathrm{L}}\right)$ of 13 PAHs were also determined using the gas chromatographic retention time technique. Activity coefficients in octanol calculated using $K_{\mathrm{OA}}$ and $P_{\mathrm{L}}$ ranged between 3.2 and 6.2 indicating near-ideal solution behavior.

Atmospheric concentrations measured in this study in Izmir, Turkey were used to investigate the partitioning of PAHs between particle and gas-phases. Experimental gas-particle partition coefficients $\left(K_{\mathrm{p}}\right)$ were compared to the predictions of $K_{\mathrm{OA}}$ absorption and $K_{\mathrm{SA}}$ (soot-air partition coefficient) models. Octanol-based absorptive partitioning model predicted lower partition coefficients especially for relatively volatile PAHs. Ratios of measured/modeled partition coefficients ranged between 1.1 and $15.5(4.5 \pm 6.0$, average $\pm \mathrm{SD})$ for $K_{\mathrm{OA}}$ model. $K_{\mathrm{SA}}$ model predictions were relatively better and measured to modeled ratios ranged between 0.6 and $5.6(2.3 \pm 2.7$, average $\pm \mathrm{SD})$.
\end{abstract}

(C) 2006 Elsevier Ltd. All rights reserved.

Keywords: PAHs; Vapor pressure; Octanol-air partition coefficient; Gas/particle partitioning

\section{Introduction}

Polycyclic aromatic hydrocarbons (PAHs) contain two to eight fused aromatic rings and they are

\footnotetext{
*Corresponding author. Tel.: + 902324127122 ; fax: +902324530922 .

E-mail address: mustafa.odabasi@deu.edu.tr (M. Odabasi).
}

formed as a result of incomplete combustion of fuels. There are hundreds of individual PAHs in the environment, however, only 16 compounds are included in the priority pollutants list of US EPA that are commonly monitored in the environment (EPA, 2003).

PAHs are found in the ambient air in gas phase and as sorbed to aerosols. The fate, transport and 
removal of PAHs from the atmosphere by dry and wet deposition processes are strongly influenced by their gas-particle partitioning (Bidleman, 1988). Considerable research has been conducted over the past decades on gas-particle partitioning of semivolatile organic compounds (SOCs). Adsorption onto particle surface and absorption into aerosol organic matter (OM) are the two proposed mechanisms describing this process. For many years, the partitioning has been described with an empirical relationship based on the supercooled liquid vapor pressure $\left(P_{\mathrm{L}}\right)$ (Pankow, 1987). Recently, absorptive partitioning of SOCs into the OM phase in atmospheric aerosols based on the octanol-air partititon coefficient $\left(K_{\mathrm{OA}}\right)$ has received much attention (Finizio et al., 1997; Harner and Bidleman, 1998a). The octanol-air partition coefficient is also a key descriptor of chemical partitioning between the atmosphere and other environmental organic phases such as soil and vegetation (Harner et al., 2000; Shoeib and Harner, 2002).

The gas chromatographic (GC) retention time method for the determination of supercooled liquid vapor pressure of SOCs has been commonly used (Lei et al., 1999, 2002; Wong et al., 2001). Most conventional methods used for vapor pressure measurement (i.e., gas saturation and effusion) yield the vapor pressure of the solid substance, whereas the GC retention time method directly gives the vapor pressure of supercooled liquid. The GC retention time method is recommended as one of the most suitable methods for the determination of the vapor pressure of low volatility compounds because it allows the relatively rapid determination of temperature dependent vapor pressures of many compounds (Lei et al., 2002). However, the method's success depends on the availability of reliable vapor pressure data for similar compounds to serve as standard reference and calibration compounds.

The conventional method for determining $K_{\mathrm{OA}}$ values for SOCs is the generator column method. The method has been used extensively to measure the $K_{\mathrm{OA}}$ of various SOCs (Harner and Mackay, 1995; Harner and Bidleman, 1996 1998b; Harner et al., 2000; Harner and Shoheib, 2002). However, the generator column method requires long experimental periods, especially at low temperatures and for compounds with low volatility, and requires several analytical steps having the potential to introduce error to the measured $K_{\mathrm{OA}}$ value (Wania et al., 2002). Therefore, an alternative method that allows the reliable estimation of $K_{\mathrm{OA}}$ values from easily and reproducibly measured substance properties is desirable (Wania et al., 2002). Recent studies have indicated that relative GC retention times or GC capacity factors on a non-polar stationary phase can be used to determine the $K_{\mathrm{OA}}$ and the energy of phase transfer between octanol and gas phase $\left(\Delta U_{\mathrm{OA}}\right)$ for non-polar SOCs (Su et al., 2002; Wania et al., 2002). The only requirements for this method are knowledge of the temperature-dependent $K_{\mathrm{OA}}$ of a standard reference compound and directly measured $K_{\mathrm{OA}}$ values for a sufficient number of calibration compounds (Wania et al., 2002). The study by Wania et al. (2002) showed that the GC retention time technique is capable of predicting the $K_{\mathrm{OA}}$ of polychlorinated benzenes, biphenyls, and naphthalenes as well as polybrominated diphenyl ethers (PBDEs) within the environmentally relevant temperature range with an average deviation from directly measured values of $<0.2 \log$ units.

$K_{\mathrm{OA}}$ values for only selected PAHs (fluorene, phenanthrene, pyrene, and fluoranthene) were previously measured by Harner and Bidleman (1998b). In this study, temperature-dependent $K_{\mathrm{OA}}$ values for 11 additional PAHs and supercooled liquid vapor pressures of $13 \mathrm{PAHs}$ were determined using the GC retention time method. Atmospheric PAH concentrations were also measured in Izmir, Turkey to investigate their phase partitioning.

\section{Experimental}

\subsection{Octanol-air partition coefficients and supercooled liquid vapor pressure}

A GC (Agilent 6890N) equipped with a mass selective detector (Agilent 5973N MSD) and a capillary column with a non-polar stationary phase (HP5-ms, $30 \mathrm{~m}, 0.25 \mathrm{~mm}, 0.25 \mu \mathrm{m}$ ) was used to determine the isothermal retention times of PAHs. The injector, quadropole, and ion source temperatures were 250,150 , and $230^{\circ} \mathrm{C}$, respectively. High purity helium was used as the carrier gas at constant flow mode with a linear velocity of $35 \mathrm{~cm} \mathrm{~s}^{-1}$. Two PAH solutions (at $4 \mu \mathrm{g} \mathrm{mL}^{-1}$ ) were used. The first solution contained seven PAHs (acenaphthylene, acenaphthene, fluorene, phenanthrene, anthracene, fluoranthene, pyrene) and the second solution contained nine PAHs (pyrene, benz $[a]$ anthracene, chrysene, benzo[b]fluoranthene, benzo[k]fluoranthene, benzo $[a]$ pyrene, indeno[1,2,3-cd]pyrene, dibenz $[a, h]$ anthracene, and benzo $[g, h, i]$ perylene). 
The first group was run at nine different temperatures $\left(150-210^{\circ} \mathrm{C}\right)$ while the second group was run at seven temperatures $\left(220-250^{\circ} \mathrm{C}\right)$ in triplicate. The MSD was run in full scan mode and PAHs were identified using spectral library search.

Isothermal retention times of several additional nonpolar compounds having directly measured $K_{\mathrm{OA}}$ values (i.e., organochlorine pesticides, OCPs and PBDEs) were also determined using a GC-MS system (Agilent 6890N GC and Agilent 5973 inert MSD) and a capillary column (HP5-ms, $30 \mathrm{~m}$, $0.25 \mathrm{~mm}, 0.25 \mu \mathrm{m})$. The OCP solution $\left(10 \mu \mathrm{g} \mathrm{mL}^{-1}\right)$ contained 10 compounds ( $\alpha$-hexachlorocyclohexane, endosulfan I, aldrin, dieldrin, $\alpha$-chlordane, $\gamma$ chlordane, trans-nonachlor, cis-nonachlor, heptachlor, and $\mathrm{p}, \mathrm{p}^{\prime}$-dichlorodiphenyltrichloroethane (p, $\mathrm{p}^{\prime}$-DDT) ) and the PBDE solution $\left(100 \mathrm{ng} \mathrm{mL}^{-1}\right)$ contained five compounds $\left(2,4,4^{\prime}\right.$-tribromodiphenyl ether, 2,2',4,4'-tetrabromodiphenyl ether, 2,2',4,4',5pentabromodiphenyl ether, 2,2',4,4',6-pentabromodiphenyl ether, 2,2',4,4'5,6'-hexabromodiphenyl ether) and $\mathrm{p}, \mathrm{p}^{\prime}$-DDT as the reference compound. Isothermal retention times were determined at eight different temperatures (between $180-250^{\circ} \mathrm{C}$ for OCPs and $220-255^{\circ} \mathrm{C}$ for PBDEs) in triplicate. The MSD was run in full scan mode for OCPs and in selected ion monitoring mode for PBDEs. OCPs and PBDEs were used along with fluorene, phenanthrene, and fluoranthene for the calibration of the method.

\subsection{Ambient air samples}

\subsubsection{Sample collection}

Fourteen ambient air samples were collected between March 17-24 and July 15-22, 2004 on the roof of a $4 \mathrm{~m}$ high building located at a residential/ commercial urban area close to the center of Izmir, Turkey. There are nearby densely populated residential areas and a busy highway $50 \mathrm{~m}$ away from the sampling site. Meteorological data were obtained from a $10 \mathrm{~m}$ high tower in the Kaynaklar campus of the Dokuz Eylul University, Izmir, Turkey that is located a few kilometers away from the urban sampling site.

Air samples were collected using a modified highvolume sampler, Model GPS-11 (Thermo-Andersen Inc.). Particles were collected on $10.5-\mathrm{cm}$ diameter quartz filters while the gas phase compounds were collected using a cartridge containing XAD-2 resin placed between layers of polyurethane foam (PUF). Concurrently, samples were collected on 11-cm diameter glass fiber filters using another high volume sampler to determine total suspended particulate matter (TSP) concentration and its organic matter (OM) content. Average sampling time was $22 \mathrm{~h}$. Average sampling volumes were $277 \pm 62$ and $94 \pm 13 \mathrm{~m}^{3}$ for PAH and TSP samples, respectively.

\subsubsection{Sample preparation and analysis}

Prior to sampling, quartz filters were wrapped loosely with aluminum foil and they were baked overnight at $450{ }^{\circ} \mathrm{C}$ to remove any organic residues. PUF cartridges were cleaned by Soxhlet extraction using 1:1 acetone:hexane mixture for $12 \mathrm{~h}$. Then, the cartridges were wrapped loosely with aluminum foil, dried in an oven at $70{ }^{\circ} \mathrm{C}$, and they were stored in glass jars capped with Teflon-lined lids.

Collected samples were spiked with deuterated surrogate standards (phenanthrene- $d_{10}$, chrysene$\mathrm{d}_{10}$, and perylene- $\mathrm{d}_{12}$ ) and Soxhlet extracted with a mixture of dichloromethane (DCM): petroleum ether (PE) (20:80) for $12 \mathrm{~h}$. All sample extracts were concentrated and transferred into hexane using a rotary evaporator and a high purity stream of nitrogen. After volume reduction to $2 \mathrm{~mL}$ and transfer into hexane, sample extracts were cleaned up on alumina-silicic acid columns containing $3 \mathrm{~g}$ silicic acid (3\% water) and $2 \mathrm{~g}$ alumina (6\% water). The column was prewashed with $20 \mathrm{~mL}$ DCM followed by $20 \mathrm{~mL}$ PE. The sample in $2 \mathrm{~mL}$ hexane was added to the top of column, polychlorinated naphthalenes, and polychlorinated biphenyls were eluted with $25 \mathrm{~mL}$ PE (fraction 1). PAHs were eluted with $20 \mathrm{~mL}$ DCM (fraction 2). For both fractions the solvent was exchanged into hexane, and the final sample volume was adjusted to $1 \mathrm{~mL}$ by nitrogen blow-down.

The samples were analyzed with a GC (Agilent $6890 \mathrm{~N}$ ) equipped with a mass selective detector (Agilent 5973 inert MSD). A capillary column (HP5-ms, $30 \mathrm{~m}, 0.25 \mathrm{~mm}, 0.25 \mu \mathrm{m}$ ) was used. The initial oven temperature was held at $50^{\circ} \mathrm{C}$ for $1 \mathrm{~min}$ and raised to $200{ }^{\circ} \mathrm{C}$ at $25^{\circ} \mathrm{C} \mathrm{min}^{-1}, 200-300^{\circ} \mathrm{C}$ at $8^{\circ} \mathrm{C} \mathrm{min}^{-1}$, held for $5.5 \mathrm{~min}$. The injector, ion source, and quadrupole temperatures were 295, 300 , and $180^{\circ} \mathrm{C}$, respectively. High purity helium was used as the carrier gas at constant flow mode $\left(1.5 \mathrm{~mL} \mathrm{~min}^{-1}, 45 \mathrm{~cm} \mathrm{~s}^{-1}\right.$ linear velocity) (Szelewski, 2003). The MSD was run in selected ion-monitoring mode. Compounds were identified based on their retention times, target and qualifier 
ions. Quantification was based on internal standard calibration procedure.

Surrogate recoveries of PAHs ranged from $60 \pm 18 \%$ (phenanthrene- $\mathrm{d}_{10}$ ) to $88 \pm 24 \%$ (perylene- $\left.\mathrm{d}_{12}\right)$. Instrumental detection limits were determined from linear extrapolation from the lowest standard in calibration curve using the area of a peak having a signal/noise ratio of 3 . The quantifiable PAH amount was approximately $0.15 \mathrm{pg}$ for $1 \mu \mathrm{L}$ injection. Blank PUF cartridges and filters were routinely placed in the field to determine if there was any contamination during sample handling and preparation. For the compounds detected in blanks the limit of detection of the method (LOD) was defined as the mean blank mass plus three standard deviations. Instrumental detection limit was used for the compounds that were not detected in blanks. LODs for PAHs ranged from $0.15 \mathrm{pg}$ (indeno $[1,2,3-c d]$ pyrene) to $252 \mathrm{ng}$ (phenanthrene) for PUFs and from $2 \mathrm{pg}$ (benz[ $a]$ anthracene) to $143 \mathrm{ng}$ (phenanthrene) for filters. In general, PAH amounts in the samples were substantially higher than LODs. Sample quantities exceeding the LOD were quantified and blank-corrected by subtracting the mean blank amount from the sample amount.

Prior to sampling for TSP, glass fiber filters were wrapped loosely with aluminum foil and they were baked overnight at $450{ }^{\circ} \mathrm{C}$ to remove any organic residues. They were then allowed to cool to room temperature in a desiccator and were weighed using a microbalance capable of weighing $0.1 \mathrm{mg}$. After sample collection filters were kept in a desiccator overnight and they were reweighed. TSP was determined by subtracting the initial weight from the final weight. To determine the OM content of the particles, filters were then baked for $1 \mathrm{~h}$ at $450{ }^{\circ} \mathrm{C}$, allowed to cool to room temperature in a desiccator, and weighed. OM was determined by subtracting the final weight (after baking) from the initial weight (before baking). Concurrent blank filters were run for each sample to account for probable interferences (i.e., weight loss of filters at high temperatures) in $\mathrm{OM}$ determination.

\section{Data analysis}

\subsection{Octanol-air partition coefficient}

The retention time of a substance on a GC column $\left(t_{\mathrm{R}}\right)$ is proportional to partition coefficient between stationary phase and gas phase $\left(K_{\mathrm{SG}}\right)$. For a compound $i$ and a reference compound eluted on the same GC column the following can be written (Wania et al., 2002) as

$K_{\mathrm{SG} i} / K_{\mathrm{SGref}}=t_{\mathrm{R} i} / t_{\mathrm{Rref}}$.

For an appropriate stationary phase, the partitioning equilibrium between stationary phase and gas phase may be similar to the partitioning equilibrium between octanol and air. This assumes that the ratio of the activity coefficients of compound $i$ and of the reference compound in octanol ( $\left.\zeta_{\mathrm{OCT} i} / \zeta_{\mathrm{OCT} \text { ref }}\right)$ is equal to the ratio of activity coefficients of these two compounds in the stationary phase $\left(\zeta_{\mathrm{S} i} / \zeta_{\mathrm{Sref}}\right)$. In terms of equilibrium partition coefficients:

$K_{\mathrm{OA} i} / K_{\mathrm{OAref}}=K_{\mathrm{SG} i} / K_{\mathrm{SGref}}$

Using Eqs. (1) and (2), $K_{\mathrm{OA}}$ of a compound $i$ and of a reference compound can be related to their retention times $\left(t_{\mathrm{R} i}\right.$ and $\left.t_{\mathrm{Rref}}\right)$ on the same $\mathrm{GC}$ column as

$K_{\mathrm{OA} i} / K_{\mathrm{OAref}}=t_{\mathrm{R} i} / t_{\mathrm{Rref}}$.

Using Eq. (3) and the Van't Hoff equation that expresses the temperature dependence of $K_{\mathrm{OA}}$, Wania et al. (2002) derived the following:

$\ln K_{\mathrm{OA} i}=\left(\Delta U_{\mathrm{OA} i} / \Delta U_{\mathrm{OAref}}\right) \ln K_{\mathrm{OAref}}+C$,

$$
\begin{aligned}
\ln \left(t_{\mathrm{R} i} / t_{\mathrm{Rref}}\right) & =\left[\left(\Delta U_{\mathrm{OA} i} / \Delta U_{\mathrm{OAref}}\right)-1\right] \ln K_{\mathrm{OAref}}+C \\
& =S \ln K_{\mathrm{OAref}}+C,
\end{aligned}
$$

where $\Delta U_{\mathrm{OA}}\left(\mathrm{kJ} \mathrm{mol}^{-1}\right)$ is the internal energy of phase transfer between octanol and air and $C$ is the integration constant. It is assumed that the energies of phase transfer are independent of temperature in the temperature range extending from environmentally relevant range to the temperatures of GC runs.

A plot of $\ln \left(t_{\mathrm{R} i} / t_{\mathrm{Rref}}\right)$ versus $\ln K_{\mathrm{OAref}}$ gives a straight line with slope $S=\left[\left(\Delta U_{\mathrm{OA} i} / \Delta U_{\mathrm{OAref}}\right)-1\right]$ and intercept $C$ (Eq. (5)). $\left(t_{\mathrm{R} i} / t_{\mathrm{Rref}}\right)$ is the relative retention time at the temperature where the reference compound has the octanol-air partition coefficient $\left(K_{\mathrm{OAref}}\right)$. The $K_{\mathrm{OA} i}$ of compound $i$ at a reference temperature was obtained using Eq. (4) where $K_{\mathrm{OAref}}$ is the $K_{\mathrm{OA}}$ of the reference compound at that temperature. $\left(\Delta U_{\mathrm{OA} i} / \Delta U_{\mathrm{OAref}}\right)=S+1$ and $C$ were obtained from the slope and intercept of Eq. (5).

In this study, pyrene was used as the standard reference compound to determine the $K_{\mathrm{OA} i}$ for other PAHs. Using the generator column technique, Harner and Bidleman (1998b) measured $K_{\mathrm{OA}}$ values for selected PAHs (fluorene, phenanthrene, pyrene, 
and fluoranthene) as a function of temperature $(T, K)$. The following equation was obtained for pyrene:

$\log K_{\mathrm{OA}}=-4.56+3985(T, K)^{-1}, \quad r^{2}=0.990$.

Eq. (6) was used to calculate $K_{\text {OAref }}$ values in Eqs. (4) and (5) at the temperatures that isothermal $\mathrm{GC}$ retention times were determined.

\subsection{Supercooled liquid vapor pressures}

$P_{\mathrm{L}}$ values were determined from the GC retention times following the procedure used by Lei et al. (2002) and Wong et al. (2001). For each compound, a vapor pressure $\left(P_{\mathrm{L}-\mathrm{GC}}\right)$ at $25^{\circ} \mathrm{C}$ was calculated using:

$\ln P_{\mathrm{L}-\mathrm{GC}}=\left(\Delta H_{\text {vap }} / \Delta H_{\text {vap-ref }}\right) \ln P_{\text {Lref }}+C$,

where $P_{\text {Lref }}(\mathrm{Pa})$ and $\Delta H_{\text {vap-ref }}\left(\mathrm{kJ} \mathrm{mol}^{-1}\right)$ are the liquid phase vapor pressure at $25^{\circ} \mathrm{C}$ and the enthalpy of vaporization of a standard reference compound. The enthalpies of vaporization are assumed to be constant over the studied temperature range $\left(25^{\circ} \mathrm{C}\right.$ to temperatures of $\mathrm{GC}$ retention time measurements). The ratio of enthalpies ( $\Delta H_{\text {vap }} /$ $\left.\Delta H_{\text {vap-ref }}\right)$ and the constant $C$ in Eq. (7) were obtained by linearly regressing the logarithm of the ratios of the measured isothermal $\mathrm{GC}$ retention times $\left(t_{\mathrm{R}} / t_{\mathrm{Rref}}\right)$ at each temperature against the logarithm of the vapor pressure of a reference compound at that temperature using the following relation (Wong et al., 2001; Lei et al., 2002):

$$
\ln \left(t_{\mathrm{R}} / t_{\text {Rref }}\right)=\left[1-\left(\Delta H_{\text {vap }} / \Delta H_{\text {vap-ref }}\right)\right] \ln P_{\text {Lref }}-C .
$$

Eq. (8) assumes that the infinite dilution activity coefficients in the stationary phase of the GC column are the same for the analyte and the compound used as reference. Since this is an approximation, $P_{\mathrm{GC}}$ may not be always identical to supercooeled liquid vapor pressure $\left(P_{\mathrm{L}}\right)$. Therefore, calibration of the method with closely related compounds is recommended (Wong et al., 2001; Lei et al., 2002).

In this study, pyrene and benz $[a]$ anthracene were used as standard reference compounds. Lei et al. (2002) recently compiled several determinations of temperature dependent solid vapor pressures $\left(P_{\mathrm{S}}\right)$ for these compounds. $P_{\mathrm{S}}$ was converted to $P_{\mathrm{L}}$ using the values for the entropy of fusion and melting point temperature and regressed against reciprocal absolute temperature. Following equations were obtained (Lei et al., 2002):

$\log P_{\mathrm{L}}(\mathrm{Pa})=11.70-4164(T, K)^{-1}$,

$r^{2}=0.999$ (pyrene),

$\log P_{\mathrm{L}}(\mathrm{Pa})=10.87-4269(T, K)^{-1}$,

$r^{2}=0.991$ (benz $[a]$ anthracene),

$P_{\text {Lref values in Eqs. (7) and (8) were calculated using }}$ Eqs. (9) and (10).
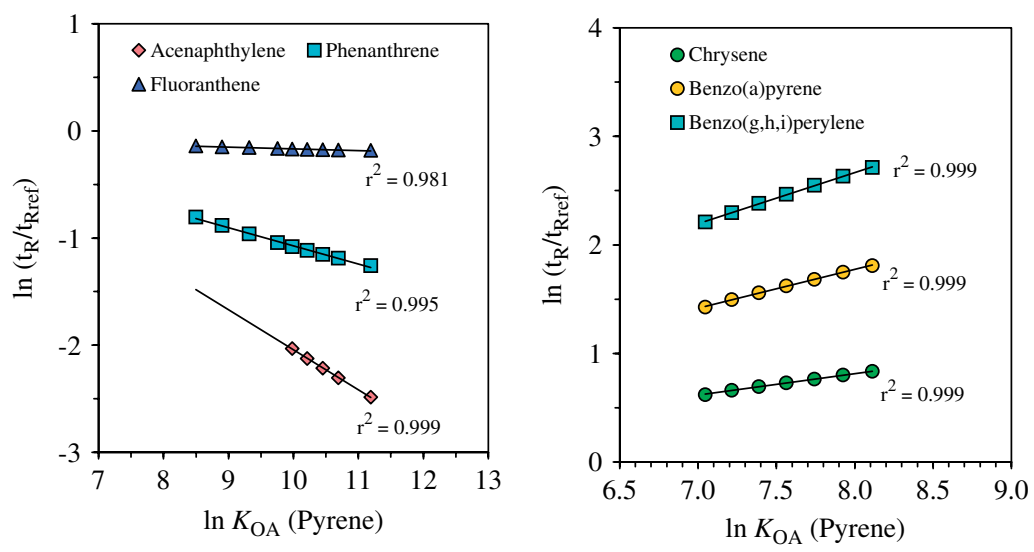

Fig. 1. Relationships between the logarithm of the ratio of the retention times of selected PAHs to the retention time of the standard reference compound (pyrene) at five to nine temperatures and the $\ln K_{\mathrm{OA}}$ value of pyrene at these temperatures calculated from Eq. (5). 


\section{Results and discussion}

\subsection{Octanol-air partition coefficient}

An example of the relationships between $\ln \left(t_{\mathrm{R}} / t_{\mathrm{Rref}}\right)$ and $\ln K_{\text {OAref }}$ is presented in Fig. 1 (Eq. (5)). These relationships were highly linear for all compounds with very high coefficients of determination $\left(r^{2}\right)$. Table 1 lists determined octanol-air partition coefficients ( $K_{\mathrm{OA}-\mathrm{GC}}$ and $\left.K_{\mathrm{OA}}\right)$ of PAHs at $25^{\circ} \mathrm{C}$ as well as the intercepts (A) and slopes (B) of the temperature regressions:

$\log K_{\mathrm{OA}}=A+B /(T, K)$.

The internal energies of phase transfer between octanol and air $\left(\Delta U_{\mathrm{OA}}\right)$ are also presented. The $K_{\mathrm{OA}-\mathrm{GC}}$ values were highly reproducible as indicated by the small relative standard deviations (0.3-4.7\%) calculated from independent determinations $(n=3)$.

$K_{\mathrm{OA}-\mathrm{GC}}$ values for OCPs and PBDEs were also determined using $\mathrm{p}, \mathrm{p}^{\prime}$-DDT as the standard reference compound. Fig. 2 shows that there is a strong correlation between the directly measured $\log K_{\mathrm{OA}}$ values (at $25^{\circ} \mathrm{C}$ ) of PAHs (Harner and Bidleman, 1998b), OCPs (Shoeib and Harner, 2002), and PBDEs (Harner and Shoheib, 2002)

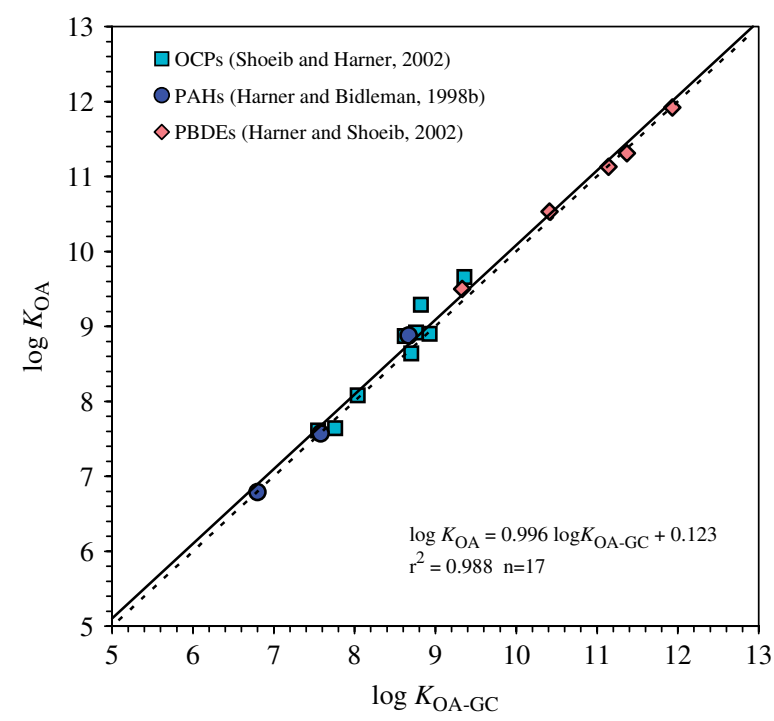

Fig. 2. Relationship between the directly measured $K_{\mathrm{OA}}$ values for OCPs $(n=9)$, PAHs $(n=3)$, and PBDEs $(n=5)$ at $25^{\circ} \mathrm{C}$ and $K_{\mathrm{OA}-\mathrm{GC}}$ values derived from $\mathrm{GC}$ retention times. The dashed line represents a 1:1 relationship, the solid line is the fit through the data points.

Table 1

Uncalibrated $\left(K_{\mathrm{OA}-\mathrm{GC}}\right.$, average $\left.\pm \mathrm{SD}, n=3\right)$ and calibrated $\left(K_{\mathrm{OA}}\right.$, average \pm propagated error) octanol-air partition coefficients for PAHs at $25^{\circ} \mathrm{C}$ determined from gas chromatographic retention times using pyrene as reference, energies of phase transfer $\left(\Delta U_{\mathrm{OA}}\right.$, average \pm propagated error), regression parameters for Eq. (11), and calculated $K_{\mathrm{OA}}$ values from dimensionless Henry's law constant $\left(H^{\prime}\right)$ and octanol-water partition coefficient $\left(K_{\mathrm{OW}}\right)$

\begin{tabular}{|c|c|c|c|c|c|c|c|c|c|}
\hline & $\log K_{\mathrm{OA-GC}}$ & $\log K_{\mathrm{OA}}$ & $B$ & $A$ & $\Delta U_{\mathrm{OA}}\left(\mathrm{kJ} \mathrm{mol}^{-1}\right)$ & $\log K_{\mathrm{OW}}$ & $H^{\prime}$ & $\log K_{\mathrm{OA}}$ (calc.) & Factor diff. \\
\hline Acenaphthylene & $6.24 \pm 0.017$ & $6.34 \pm 0.31$ & 2476 & -1.97 & $47.4 \pm 2.8$ & $3.94^{\mathrm{a}}$ & $5.11 \times 10^{-3 e}$ & 6.23 & 1.3 \\
\hline Acenaphthene & $6.42 \pm 0.005$ & $6.52 \pm 0.31$ & 2597 & -2.20 & $49.7 \pm 3.0$ & $4.15^{\mathrm{a}}$ & $7.48 \times 10^{-3 e}$ & 6.28 & 1.7 \\
\hline Fluorene & $6.80 \pm 0.007$ & $6.90 \pm 0.32$ & 2833 & -2.61 & $54.2 \pm 3.3$ & $4.18^{\mathrm{a}}$ & $3.97 \times 10^{-3 \mathrm{e}}$ & 6.58 & 2.1 \\
\hline Phenanthrene & $7.59 \pm 0.001$ & $7.68 \pm 0.33$ & 3293 & -3.37 & $63.0 \pm 3.8$ & $4.57^{\mathrm{b}}$ & $1.73 \times 10^{-3 \mathrm{e}}$ & 7.33 & 2.2 \\
\hline Anyhracene & $7.62 \pm 0.001$ & $7.71 \pm 0.33$ & 3316 & -3.41 & $63.5 \pm 3.8$ & $4.45^{\mathrm{b}}$ & $2.28 \times 10^{-3 \mathrm{e}}$ & 7.09 & 4.2 \\
\hline Fluoranthene & $8.67 \pm 0.003$ & $8.76 \pm 0.35$ & 3904 & -4.34 & $74.8 \pm 4.4$ & $5.22^{\mathrm{c}}$ & $7.89 \times 10^{-4 \mathrm{e}}$ & 8.32 & 2.8 \\
\hline Benz $[a]$ anthracene & $10.20 \pm 0.005$ & $10.28 \pm 0.38$ & 4746 & -5.64 & $90.9 \pm 5.4$ & $5.79^{\mathrm{b}}$ & $4.91 \times 10^{-4 \mathrm{e}}$ & 9.10 & 15.1 \\
\hline Chrysene & $10.22 \pm 0.004$ & $10.30 \pm 0.38$ & 4754 & -5.65 & $91.0 \pm 5.4$ & $5.73^{\mathrm{b}}$ & $2.14 \times 10^{-4 \mathrm{e}}$ & 9.40 & 7.9 \\
\hline Benzo $[b]$ fluoranthene & $11.26 \pm 0.003$ & $11.34 \pm 0.41$ & 5285 & -6.40 & $101.2 \pm 6.0$ & $6.11^{\mathrm{a}}$ & $2.69 \times 10^{-5 f}$ & 10.68 & 4.6 \\
\hline Benzo $[k)$ fluoranthene & $11.29 \pm 0.004$ & $11.37 \pm 0.41$ & 5301 & -6.42 & $101.5 \pm 6.0$ & $6.11^{\mathrm{a}}$ & $2.39 \times 10^{-5 \mathrm{f}}$ & 10.73 & 4.4 \\
\hline Benzo $[a]$ pyrene & $11.48 \pm 0.005$ & $11.56 \pm 0.41$ & 5382 & -6.50 & $103.1 \pm 6.1$ & $6.13^{\mathrm{a}}$ & $1.87 \times 10^{-5 \mathrm{f}}$ & 10.86 & 3.5 \\
\hline Indeno $[1,2,3-c d]$ pyrene & $12.36 \pm 0.002$ & $12.43 \pm 0.43$ & 5791 & -7.00 & $110.9 \pm 6.6$ & $6.72^{\mathrm{b}}$ & $1.43 \times 10^{-5 f}$ & 11.56 & 7.4 \\
\hline Dibenz $[a, h]$ anthracene & $12.52 \pm 0.002$ & $12.59 \pm 0.43$ & 5887 & -7.17 & $112.7 \pm 6.7$ & $6.50^{\mathrm{b}}$ & $6.03 \times 10^{-7 \mathrm{~g}}$ & 13.67 & 0.7 \\
\hline Benzo $[g, h, i]$ perylene & $12.48 \pm 0.004$ & $12.55 \pm 0.43$ & 5834 & -7.03 & $111.7 \pm 6.6$ & $6.90^{\mathrm{d}}$ & $1.35 \times 10^{-5 f}$ & 11.77 & 6.0 \\
\hline
\end{tabular}

\footnotetext{
${ }^{\mathrm{a}}$ VCCL (2004).

${ }^{\mathrm{b}} \mathrm{NLM}$ (2004).

${ }^{\mathrm{c}}$ Finizio et al. (1997).

${ }^{\mathrm{d}}$ Jonker and Koelmans (2002).

${ }^{\mathrm{e}}$ Bamford et al. (1999).

${ }^{\mathrm{f}}$ Ten Hulscher et al. (1992).

${ }^{g}$ EPA (1996).
} 
versus $K_{\mathrm{OA}-\mathrm{GC}}$ :

$$
\begin{aligned}
\log K_{\mathrm{OA}}= & (0.996 \pm 0.028) \log K_{\mathrm{OA}-\mathrm{GC}} \\
& +(0.123 \pm 0.256)\left(r^{2}=0.988, n=17\right)
\end{aligned}
$$

Eq. (12) was used to correct the $K_{\mathrm{OA}-\mathrm{GC}}$ values for the systematic deviations from directly measured $K_{\mathrm{OA}}$ values (Table 1). $K_{\mathrm{OA}}$ values were slightly higher than $K_{\mathrm{OA}-\mathrm{GC}}$ values $(1.17-1.25$ times). The standard deviations given for $\log K_{\mathrm{OA}}$ values in Table 1 were derived from the standard error of the slope and intercept of the Eq. (12) and the standard deviations of the $\log K_{\mathrm{OA}-\mathrm{GC}}$ values by error propagation. The error $(3.5-5 \%)$ is dominated by the uncertainty of the coefficients in the calibration equation rather than by the uncertainty in $K_{\mathrm{OA}-\mathrm{GC}}$ determination.

$K_{\mathrm{OA}}$ values for PAHs were also calculated as the ratio of octanol/water partition coefficient $\left(K_{\mathrm{OW}}\right)$ to dimensionless Henry's law constant $\left(\mathrm{H}^{\prime}\right)$ (Table 1$)$. The $K_{\mathrm{OA}} / K_{\mathrm{OA}}$ (calculated) ratio ranged between 0.7 and 15.1 and the ratios were generally higher for nonvolatile PAHs (benz $[a]$ anthracene through benzo[g,h,i]perylene). Similar deviations between the calculated and directly measured $K_{\mathrm{OA}}$ values were reported by previous studies (Harner and Mackay, 1995; Harner and Bidleman, 1998b; Shoeib and Harner, 2002).

The internal energies of phase transfer between octanol and air $\left(\Delta U_{\mathrm{OA}}\right)$ were calculated as $(2.303$ B R) using the slope of Eq. (11) (B) and ideal gas constant $(R)$ (Table 1). $\Delta U_{\mathrm{OA}}$ values ranged between 47.4 and $112.7 \mathrm{~kJ} \mathrm{~mol}^{-1} . \Delta U_{\mathrm{OA}}$ values calculated in this study for phenanthrene and fluoranthene were 63.0 and $74.8 \mathrm{~kJ} \mathrm{~mol}^{-1}$, respectively, and they agreed well with the values reported by Harner and Bidleman (1998b) (75.5 and $84.6 \mathrm{~kJ} \mathrm{~mol}^{-1}$ ). However, $\Delta U_{\mathrm{OA}}$ for fluorene $\left(54.2 \mathrm{~kJ} \mathrm{~mol}^{-1}\right)$ was lower than the previously reported value $\left(82.9 \mathrm{~kJ} \mathrm{~mol}^{-1}\right)$.

\subsection{Supercooled liquid vapor pressures}

Table 2 lists determined vapor pressures $\left(P_{\mathrm{L}-\mathrm{GC}}\right.$ and $P_{\mathrm{L}}$ ) of PAHs at $25^{\circ} \mathrm{C}$ as well as the intercepts $\left(b_{\mathrm{L}}\right)$ and slopes $\left(m_{\mathrm{L}}\right)$ of the temperature regressions:

$\log P_{\mathrm{L}}(\mathrm{Pa})=m_{\mathrm{L}}(T, K)^{-1}+b_{\mathrm{L}}$.

Enthalpies of vaporization $\left(\Delta H_{\text {vap }}\right)$ are also listed. The $P_{\mathrm{GC}}$ values were highly reproducible as indicated by the small relative standard deviations $(0.2-1.6 \%)$ calculated from three independent determinations.

Six PAHs (acenaphthene, fluorene, phenanthrene, anthracene, fluoranthene, and chrysene) with well established vapor pressures at $25^{\circ} \mathrm{C}$ were used for calibration. $P_{\mathrm{L}}$ values of these compounds compiled by Lei et al. (2002) from previous studies were used. $P_{\mathrm{L}-\mathrm{GC}}$ values for calibration compounds determined using Eqs. (7)-(8) were regressed against $P_{\mathrm{L}}$ and the following relationship was obtained (Fig. 3):

$$
\begin{aligned}
\log P_{\mathrm{L}}(\mathrm{Pa})= & (1.069 \pm 0.016) \log P_{\mathrm{L}-\mathrm{GC}}(\mathrm{Pa}) \\
& +(0.041 \pm 0.022)\left(r^{2}=0.994, n=29\right) .
\end{aligned}
$$

\begin{tabular}{|c|c|c|c|c|c|c|}
\hline PAH & Reference compound $^{\mathrm{a}}$ & $\log P_{\mathrm{L}-\mathrm{GC}}(\mathrm{Pa})$ & $\log P_{\mathrm{L}}(\mathrm{Pa})$ & $m_{\mathrm{L}}$ & $b_{\mathrm{L}}$ & $\Delta H_{\mathrm{vap}}\left(\mathrm{kJ} \mathrm{mol}^{-1}\right)$ \\
\hline Acenaphthylene & 1 & $0.29 \pm 0.002$ & $0.35 \pm 0.02$ & -2855 & 9.93 & -54.7 \\
\hline Acenaphthene & 1 & $0.12 \pm 0.006$ & $0.17 \pm 0.02$ & -2979 & 10.17 & -57.0 \\
\hline Fluorene & 1 & $-0.26 \pm 0.006$ & $-0.24 \pm 0.02$ & -3233 & 10.61 & -61.9 \\
\hline Phenanthrene & 1 & $-1.05 \pm 0.001$ & $-1.08 \pm 0.03$ & -3726 & 11.43 & -71.3 \\
\hline Anyhracene & 1 & $-1.08 \pm 0.001$ & $-1.11 \pm 0.03$ & -3750 & 11.47 & -71.8 \\
\hline Fluoranthene & 1 & $-2.13 \pm 0.001$ & $-2.24 \pm 0.04$ & -4382 & 12.47 & -83.9 \\
\hline Chrysene & 1 & $-3.68 \pm 0.004$ & $-3.89 \pm 0.06$ & -5294 & 13.87 & -101.4 \\
\hline Benzo $[b]$ fluoranthene & 2 & $-4.53 \pm 0.005$ & $-4.80 \pm 0.08$ & -5148 & 12.48 & -98.6 \\
\hline Benzo $[k]$ fluoranthene & 2 & $-4.55 \pm 0.004$ & $-4.82 \pm 0.08$ & -5165 & 12.50 & -98.9 \\
\hline Benzo $[a]$ pyrene & 2 & $-4.75 \pm 0.005$ & $-5.04 \pm 0.08$ & -5252 & 12.59 & -100.6 \\
\hline Indeno $[1,2,3-c d]$ pyrene & 2 & $-5.62 \pm 0.004$ & $-5.97 \pm 0.09$ & -5691 & 13.13 & -109.0 \\
\hline Dibenz $[a, h]$ anthracene & 2 & $-5.78 \pm 0.003$ & $-6.14 \pm 0.10$ & -5794 & 13.31 & -110.9 \\
\hline Benzo $[g, h, i]$ perylene & 2 & $-5.74 \pm 0.005$ & $-6.10 \pm 0.10$ & -5737 & 13.15 & -109.8 \\
\hline
\end{tabular}

Table 2

Uncalibrated $\left(P_{\mathrm{L}-\mathrm{GC}}\right.$, average $\left.\pm \mathrm{SD}, n=3\right)$ and calibrated $\left(P_{\mathrm{L}}\right.$, average \pm propagated error) vapor pressures for PAHs at $25^{\circ} \mathrm{C}$ determined from gas chromatographic retention times, enthalpies of vaporization $\left(\Delta H_{\mathrm{vap}}\right)$, and regression parameters for Eq. (13)

\footnotetext{
${ }^{\mathrm{a}} 1:$ Pyrene, 2 : benz $[a]$ anthracene.
} 


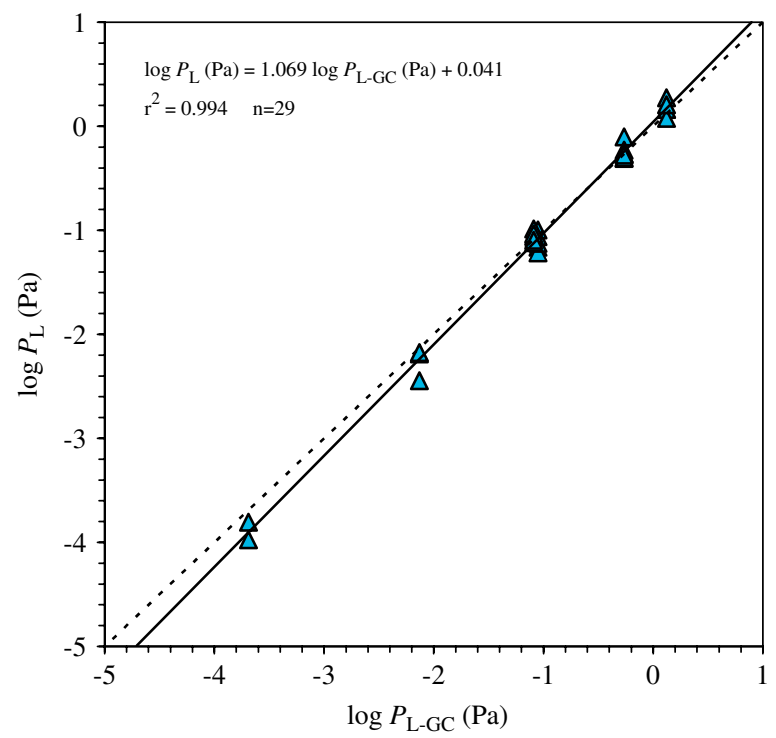

Fig. 3. Relationship between the GC determined vapor pressure $\left(P_{\mathrm{L}-\mathrm{GC}}\right)$ and the vapor pressure of supercooled liquid $\left(P_{\mathrm{L}}\right)$ derived from literature data (Lei et al., 2002) at $25^{\circ} \mathrm{C}$ for six PAHs. The dashed line represents a 1:1 relationship, the solid line is the fit through the data points.

The relationship between $P_{\mathrm{GC}}$ and $P_{\mathrm{L}}$ is highly linear, the slope is close to 1 and the intercept is close to 0 . For relatively more volatile PAHs $P_{\mathrm{L}-\mathrm{GC}}$ is slightly lower than $P_{\mathrm{L}}$ while $P_{\mathrm{L}-\mathrm{GC}}$ is higher than $P_{\mathrm{L}}$ for non-volatile PAHs, indicating that calibration procedure is necessary. The standard deviations given for $\log P_{\mathrm{L}}$ values in Table 2 were calculated by error propagation using the standard error of the slope and intercept of the Eq. (14) and the standard deviations of the $\log P_{\mathrm{L}-\mathrm{GC}}$ values. The error $(1.6-11.8 \%)$ is dominated by the uncertainty of the coefficients in the calibration equation rather than by the uncertainty in $P_{\mathrm{L}-\mathrm{GC}}$ determination.

The slope (1.339) and intercept (0.674) values of the calibration equation obtained by Lei et al. (2002) were different than those obtained in this study. The different calibration equations resulted from these two studies may be due to the different GC columns used with different non-polar stationary phases. A DB-1 column (100\% dimethylpolysiloxane) was used by Lei et al. (2002) while an HP-5ms column (5\% phenylpolysiloxane $+95 \%$ methylpolysiloxane) was used in this study. This also emphasizes that the calibration equations should be determined and used as study-specific.

$P_{\mathrm{L}}$ values determined in this study were compared to those recently reported by Lei et al. (2002). The agreement between the 10 PAHs measured in both studies was very good as indicated by high $r^{2}$, slope close to 1 , and intercept close to 0 :

$\log P_{\mathrm{L}}(\mathrm{Pa})($ Lei et al. $)=1.056 \log P_{\mathrm{L}}(\mathrm{Pa})($ this study $)$

$$
+0.052 r^{2}=0.998(n=10) \text {. }
$$

Enthalpies of vaporization $\left(\Delta H_{\text {vap }}\right)$ were calculated as $\left(2.303 m_{\mathrm{L}} R\right)$ using the slope of Eq. (13) $\left(m_{\mathrm{L}}\right)$ and ideal gas constant $(R)$ (Table 2). $\Delta H_{\text {vap }}$ values ranged between 54.7 and $110.9 \mathrm{~kJ} \mathrm{~mol}^{-1}$ and they were similar to those reported by Lei et al. (2002) $\left(63.9-99.4 \mathrm{~kJ} \mathrm{~mol}^{-1}\right)$.

The $K_{\mathrm{OA}}$ and $P_{\mathrm{L}}$ are related through the following equation (Shoeib and Harner, 2002; Xiao and Wania, 2003):

$K_{\mathrm{OA}}=C_{\mathrm{O}} / C_{\mathrm{A}}=R T / \zeta_{\mathrm{OCT}} V_{O C T} P_{\mathrm{L}}$

where $C_{\mathrm{O}}$ and $C_{\mathrm{A}}$ are the equilibrium concentrations $\left(\mathrm{mol} \mathrm{m}^{-3}\right)$ of the solute in octanol and air respectively, $R$ is the universal gas constant (8.314 $\mathrm{Pa} \mathrm{m}^{3} \mathrm{~mol}^{-1} \mathrm{~K}^{-1}$ ), $T$ is temperature $(K), \zeta_{\text {OCT }}$ the activity coefficient in octanol, $V_{\text {Ост }}$ the molar volume of octanol $\left(1.58 \times 10^{-4} \mathrm{~m}^{3} \mathrm{~mol}^{-1}\right)$, and $P_{\mathrm{L}}$ the supercooled liquid vapor pressure $(\mathrm{Pa})$. The activity coefficient in octanol is a measure of nonideal behavior due to interactions between solute

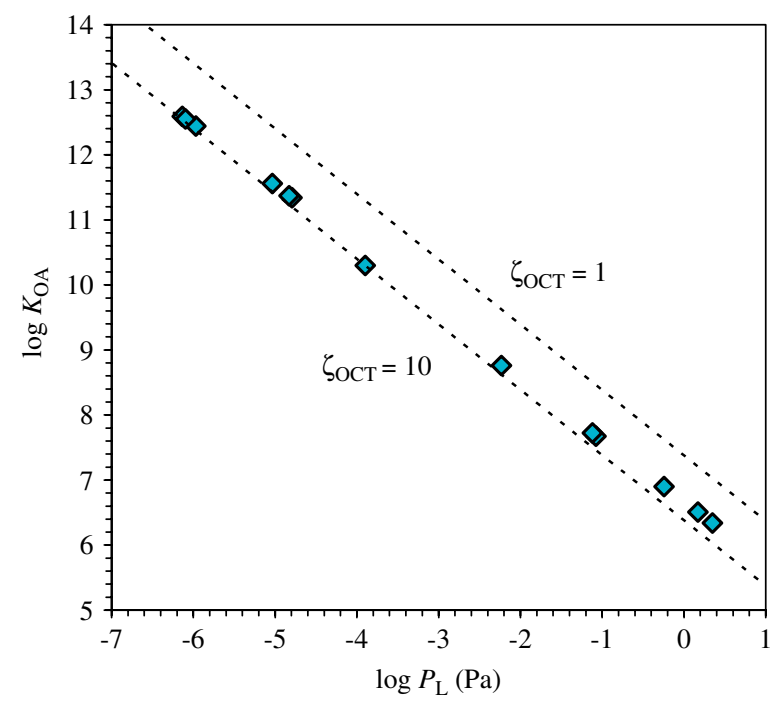

Fig. 4. Plot of octanol-air partition coefficients versus supercooled liquid vapor pressure for PAHs. $\zeta_{\text {OCT }}$ lines were calculated using Eq. (16). Regression equation is $\log K_{\mathrm{OA}}=-0.97 \log P_{\mathrm{L}}+$ $6.65\left(r^{2}=0.999, n=13\right)$. 
and octanol molecules and it approaches unity for an ideal solution (Harner and Shoheib, 2002).

Eq. (16) was used to calculate $\zeta_{\text {OCT }}$ for individual PAHs. $\zeta_{\text {OCT }}$ is similar for several classes of SOCs within the range of $1-10$ indicating near-ideal behavior (Harner and Shoheib, 2002; Xiao and Wania, 2003). A good and near 1:1 relationship between $\log K_{\mathrm{OA}}$ and $\log P_{\mathrm{L}}$ was obtained (Fig. 4). Calculated $\zeta_{\text {OCT }}$ values for PAHs ranged between 3.2 and 6.2 indicating near-ideal solution behavior.

\subsection{Ambient PAH concentrations and gas-particle partitioning}

$\Sigma_{13}$ PAHs refers to sum of the concentrations (gas + particle-phases) of the 13 measured compounds (fluorene through benzo[g,h,i]perylene). Atmospheric concentrations of $\Sigma_{13} \mathrm{PAHs}$ ranged between 42 and $630 \mathrm{ng} \mathrm{m}^{-3}\left(143 \pm 163 \mathrm{ng} \mathrm{m}^{-3}\right.$, average \pm SD). On the average $\Sigma_{13} \mathrm{PAH}$ concentrations measured in winter were approximately 5 times higher than those measured in summer. The increase in PAH emissions as a result of residential heating during winter might be the main reason for this observation.

The $\Sigma_{13} \mathrm{PAH}$ concentrations measured in this study were comparable to those measured previously in Chicago, IL by Odabasi et al. (1999) (59-863 $\mathrm{ng} \mathrm{m}^{-3}$ ) and Simcik et al. (1997) $\left(48-550 \mathrm{ng} \mathrm{m}^{-3}\right)$. Average concentrations of individual PAHs ranged between $41.7 \pm 37.0 \mathrm{ng} \mathrm{m}^{-3}$ (phenanthrene) and $1.3 \pm 1.9 \mathrm{ng} \mathrm{m}^{-3}$ (dibenz[a,h]anthracene). PAH profiles obtained in this study were similar to those observed in previous studies.

Partitioning of atmospheric organic compounds between the gas and particle phases is parameterized using the gas-particle partition coefficient, $K_{\mathrm{p}}$ $\left(\mathrm{m}^{3} \mu \mathrm{g}^{-1}\right)$ (Harner and Bidleman, 1998a):

$K_{\mathrm{p}}=\left(C_{\mathrm{p}} / C_{\mathrm{TSP}}\right) / C_{\mathrm{g}}$,

where $C_{\mathrm{p}}$ and $C_{\mathrm{g}}$ are the organic compound concentrations in the particulate and gas phases, respectively $\left(\mu \mathrm{g} \mathrm{m}^{-3}\right.$ ), and $C_{\mathrm{TSP}}$ is the concentration of total suspended particles in the air $\left(\mu \mathrm{g} \mathrm{m}^{-3}\right)$.

The octanol-air partitioning coefficient $\left(K_{\mathrm{OA}}\right)$ can be used to predict $K_{\mathrm{p}}$ with the assumption of predominant distribution process is absorption (Harner and Bidleman, 1998a). The relationship between $K_{\mathrm{P}}$ and $K_{\mathrm{OA}}$ is

$K_{\mathrm{P}}=\left(f_{\mathrm{OM}} \mathrm{MW}_{\text {OCT }} \zeta_{\mathrm{OCT}}\right) K_{\mathrm{OA}} /\left(\rho_{\mathrm{OCT}} \mathrm{MW}_{\mathrm{OM}} \zeta_{\mathrm{OM}} 10^{12}\right)$, where $f_{\mathrm{OM}}$ is the fraction of $\mathrm{OM}$ phase on TSP, $\mathrm{MW}_{\mathrm{OCT}}$ and $\mathrm{MW}_{\mathrm{OM}}$ are the mean molecular weights of octanol and the OM phase $\left(\mathrm{g} \mathrm{mol}^{-1}\right)$, $\rho_{\text {OCT }}$ is the density of octanol $\left(0.820 \mathrm{~kg} \mathrm{~L}^{-1}\right)$, $\zeta_{\text {OCT }}$ is the activity coefficient of the absorbing compound in octanol, $\zeta_{\mathrm{OM}}$ is the activity coefficient of the compound in the OM phase. With the assumptions that $\zeta_{\mathrm{OCT}} / \zeta_{\mathrm{OM}}$ and $\mathrm{MW}$ OCT $/ \mathrm{MW}_{\mathrm{OM}}=1$, Eq. (18) can be written as

$\log K_{\mathrm{P}}=\log K_{\mathrm{OA}}+\log f_{\mathrm{OM}}-11.91$.

Strong association of PAHs with soot particles in soot-water systems suggests that besides absorption, adsorption partitioning could also be an important sorption mechanism in the atmosphere. Therefore, the following equation for the overall gas-particle partition coefficient that accounts for both OM absorption and soot carbon adsorption was derived by Dasch and Eisenreich (2000):

$$
\begin{aligned}
K_{\mathrm{P}}=[ & \left.\left(f_{\mathrm{OM}} \mathrm{MW}_{\mathrm{OCT}} \zeta_{\mathrm{OCT}}\right) K_{\mathrm{OA}} /\left(\rho_{\mathrm{OCT}} \mathrm{MW}_{\mathrm{OM}} \zeta_{\mathrm{OM}} 10^{12}\right)\right] \\
& +\left[\left(f_{\mathrm{EC}} a_{\mathrm{EC}}\right) K_{\mathrm{SA}} / a_{\mathrm{AC}} 10^{12}\right],
\end{aligned}
$$

where $f_{\mathrm{EC}}$ is the fraction of elemental carbon in the aerosol, $a_{\mathrm{EC}}$ and $a_{\mathrm{AC}}$ are the specific surface areas of elemental carbon and activated carbon, respectively; $K_{\mathrm{SA}}$ is the soot-air partition coefficient. Elemental carbon and octanol are the surrogates for the soot carbon in adsorptive partitioning, and $\mathrm{OM}$ in absorptive partitioning, respectively.

The PAH concentrations measured in this study were used for gas-particle partitioning modeling. The experimental and modeled $K_{\mathrm{p}}$ values for individual PAHs were calculated using Eqs. (17), (19), and (20). The influence of temperature on $K_{\mathrm{OA}}$ was taken into account using Eq. (11). Dachs et al. (2004) have suggested that the thermodynamicsbased model recently reported by van Noort (2003) can be used to estimate $K_{\mathrm{SA}}$ values for PAHs as a function of supercooled liquid vapor pressure $\left(P_{\mathrm{L}}, \mathrm{Pa}\right)$ and elemental carbon specific surface area $\left(a_{\mathrm{EC}}, \mathrm{m}^{2} \mathrm{~g}^{-1}\right)$ :

$\log K_{\mathrm{SA}}=-0.85 \log P_{\mathrm{L}}+8.94-\log \left(998 / a_{\mathrm{EC}}\right)$,

$P_{\mathrm{L}}$ values as function of temperature were calculated using Eq. (13). The $a_{\mathrm{EC}}$ value $\left(62.7 \mathrm{~m}^{2} \mathrm{~g}^{-1}\right)$ was taken from a recent study by Jonker and Koelmans (2002). It was assumed that $a_{\mathrm{EC}} / a_{\mathrm{AC}}=1, f_{\mathrm{OM}}=1.6 f_{\mathrm{TOC}}$, and $f_{\mathrm{OC}} / f_{\mathrm{EC}}=3$ where $f_{\text {TOC }}$ is the fraction of total organic carbon (Dasch 


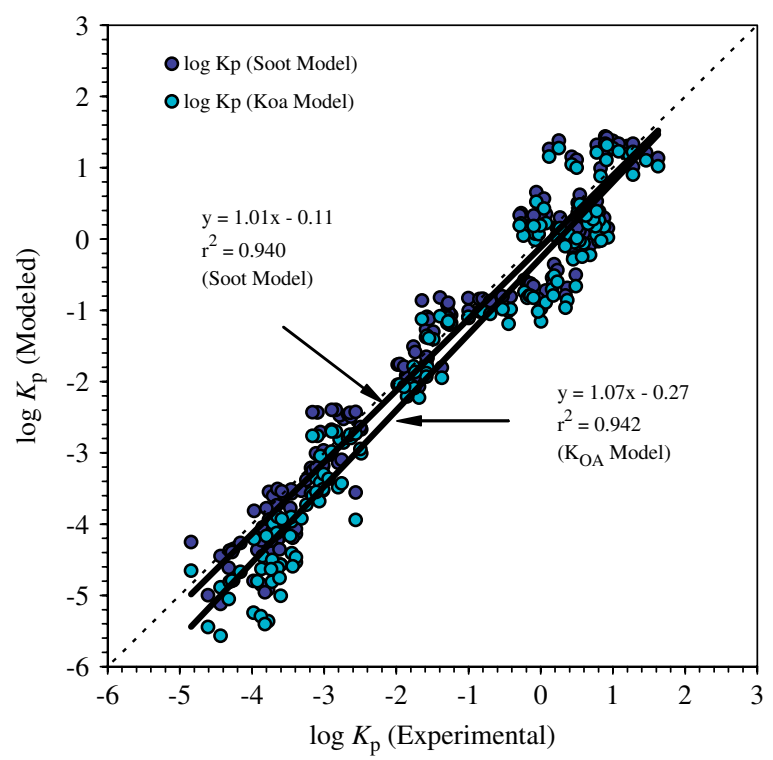

Fig. 5. Comparison of the measured and predicted $K_{\mathrm{p}}$ values by two partitioning models. The dashed line represents a $1: 1$ relationship.

and Eisenreich, 2000; Ribes et al., 2003). Under these assumptions, modeled $K_{\mathrm{p}}$ values were calculated using Eq. (19) for absorptive partitioning and Eq. (20) for both absorptive and adsorptive partitioning. The modeled $K_{\mathrm{p}}$ values were compared to the measured ones in Fig. 5.

Octanol-based absorptive partitioning model predicted lower partition coefficients especially for relatively volatile PAHs. However, overall there is a relatively good agreement between the measured $K_{\mathrm{p}}$ and soot-based model predictions. Ratios of measured/modeled partition coefficients ranged between 1.1 (chrysene) and 15.5 (fluorene) $(4.5 \pm 6.0$, average $\pm \mathrm{SD})$ for $K_{\mathrm{OA}}$ model. Soot model predictions were relatively better and measured to modeled ratios ranged between 0.6 (chrysene) and 5.6 (fluorene) $(2.3 \pm 2.7$, average $\pm S D)$. Recent studies reported that the soot based model shows good predictability at an urban site (Chicago, IL) but underestimates values at a rural site (Eagle Harbor) by an order of magnitude (Vardar et al., 2004; Galarneau et al., 2006). It was suggested that characterizing atmospheric soot, determining the temperature dependence of soot-air partitioning, and quantifying the exchangeable fraction of each PAH on aerosols will help to explain the differences between predicted and observed partition coefficients (Galarneau et al., 2006).

\section{Acknowledgments}

This work was supported in part by the scientific research fund of Dokuz Eylul University, Izmir, Turkey (Project No. 03.KB.FEN.101).

\section{References}

Bamford, H.A., Poster, D.L., Baker, JE., 1999. Temperature dependence of Henry's law constants of thirteen polycyclic aromatic hydrocarbons between 4 degrees $\mathrm{C}$ and 31 degrees C. Environmental Toxicology and Chemistry 18, 1905-1912.

Bidleman, T.F., 1988. Atmospheric processes: wet and dry deposition of organic compounds are controlled by their vapor-particle partitioning. Environmental Science and Technology 22, 361-367.

Dasch, J., Eisenreich, S.J., 2000. Adsorption onto aerosol carbon soot carbon dominates gas-particle partitioning of polycyclic aromatic hydrocarbons. Environmental Science and Technology $34,3690-3697$.

Dachs, J., Ribes, S., van Drooge, B., Grimalt, J., Eisenreich, S.J., Gustafsson, O., 2004. Response to the comment on Influence of soot carbon on the soil-air partitioning of polycyclic aromatic hydrocarbons. Environmental Science and Technology 38, 1624-1625.

EPA. EPA Appendix A to 40 CFR, Part 423-126 Priority Pollutants, 2003. Available from: http://www.epa.gov/ region01/npdes/permits/generic/prioritypollutants.pdf

EPA. Soil screening guidance: user's guide, attachment Cchemical properties for SSL development, EPA540/R-96/ 018, 1996. Available from: http://www.epa.gov/superfund/ resources/soil/attachc.pdf

Finizio, A., Mackay, D., Bidleman, T.F., Harner, T., 1997. Octanol-air partition coefficient as a predictor of partitioning of semivolatile organic chemicals. Atmospheric Environment 31, 289-2296.

Galarneau, E., Bidleman, T.F., Blanchard, P., 2006. Seasonality and interspecies differences in particle/gas partitioning of PAHs observed by the Integrated Atmospheric Deposition Network (IADN). Atmospheric Environment 40, 182-197.

Harner, T., Bidleman, T.F., 1996. Measurements of octanol-air partition coefficients for polychlorinated biphenyls. Journal of Chemical and Engineering Data 41, 895-899.

Harner, T., Bidleman, T.F., 1998a. Octanol-air partition coefficient for describing particle/gas partitioning of aromatic compounds in urban air. Environmental Science and Technology 32, 1494-1502.

Harner, T., Bidleman, T.F., 1998b. Measurement of octanol-air partition coefficients for polycyclic aromatic hydrocarbons and polychlorinated naphthalenes. Journal of Chemical and Engineering Data 43, 40-46.

Harner, T., Mackay, D., 1995. Measurements of octanol-air partition coefficients for chlorobenzenes, PCBs and DDT. Environmental Science and Technology 29, 1599-1606.

Harner, T., Shoheib, M., 2002. Measurements of octanol-air partition coefficients $\left(K_{\mathrm{OA}}\right)$ for polybrominated diphenyl ethers: predicting partitioning in the environment. Journal of Chemical and Engineering Data 47, 228-232.

Harner, T., Green, N.J.L., Jones, K.C., 2000. Measurements of octanol-air partition coefficients for PCDD/Fs: a tool in 
assessing air-soil equilibrium status. Environmental Science and Technology 34, 3109-3114.

Jonker, M.T.O., Koelmans, A.A., 2002. Sorption of polycyclic aromatic hydrocarbons and polychlorinated biphenyls to soot and soot-like materials in the aqueous environment: mechanistic considerations. Environmental Science and Technology 36, 3725-3734.

Lei, Y.D., Wania, F., Shiu, W.Y., 1999. Vapor pressures of polychlorinated naphthalenes. Journal of Chemical and Engineering Data 44, 577-582.

Lei, Y.D., Chankalal, R., Chan, A., Wania, F., 2002. Supercooled liquid vapor pressures of the polycyclic aromatic hydrocarbons. Journal of Chemical and Engineering Data 47, 801-806.

National Library of Medicine (NLM), Specialized Information Services (SIS), Toxnet. 2004. Available from: http://toxnet.nlm. nih.gov/.

Odabasi, M., Vardar, N., Tasdemir, Y., Sofuoglu, A., Holsen, T.M., 1999. Polycyclic aromatic hydrocarbons in Chicago air. The Science of the Total Environment 227, 57-67.

Pankow, J.F., 1987. Review and comparative analysis of the theories on partitioning between the gas and aerosol particulate phases in the atmosphere. Atmospheric Environment 22, 2275-2283.

Ribes, S., Van Drooge, B., Dachs, J., Gustafsson, O., Grimalt, J.O., 2003. Influence of soot carbon on the soil-air partitioning of polycyclic aromatic hydrocarbons. Environmental Science and Technology 37, 2675-2680.

Shoeib, M., Harner, T., 2002. Using measured octanol-air partition coefficients to explain environmental partitioning of organochlorine pesticides. Environmental Toxicology and Chemistry 21, 984-990.

Simcik, M.F., Zhang, H., Eisenreich, S.J., Franz, T.P., 1997. Urban contamination of the Chicago/Lake Michigan atmosphere by PCBs and PAHs during AEOLOS. Environmental Science and Technology 31, 2141-2147.
Su, Y., Lei, Y.D., Daly, G.L., Wania, F., 2002. Determination of octanol-air partition coefficient $\left(K_{\mathrm{OA}}\right)$ values for chlorobenzenes and polychlorinated naphthalenes from gas chromatographic retention times. Journal of Chemical and Engineering Data 47, 449-455.

Szelewski, M., 2003. Full-scan low level polynuclear aromatic hydrocarbon analysis using the Agilent Technologies 6890/ 5973 inert gas chromatograph/mass selective detector. Agilent Technologies Inc., Application (5989-0264N). Available from: http://www.chem.agilent.com/temp/radFD854/00045249.pdf

Ten Hulscher, T.E.M., Van Der Velde, L.E., Bruggeman, W.A., 1992. Temperature dependence of Henry's law constants for selected chlorobenzenes, polychlorinated biphenyls and polycyclic aromatic hydrocarbons. Environmental Toxicology and Chemistry 11, 1595-1603.

van Noort, P.C.M., 2003. A thermodynamics-based estimation model for adsorption of organic compounds by carbonaceous materials in environmental sorbents. Environmental Toxicology and Chemistry 22, 1179-1188.

Vardar, N., Tasdemir, Y., Odabasi, M., Noll, K.E., 2004. Characterization of atmospheric concentrations and partitioning of PAHs in the Chicago atmosphere. Science of the Total Environment 327, 163-174.

Virtual Computational Chemistry Laboratory (VCCL), 2004. Available from: http://146.107.217.178/lab/alogps/start.html

Wania, F., Lei, Y.D., Harner, T., 2002. Estimating octanol-air partition coefficients of nonpolar semivolatile organic compounds from gas chromatographic retention times. Analytical Chemistry 74, 3476-3483.

Wong, A., Lei, Y.D., Alae, M., Wania, F., 2001. Vapor pressures of polybrominated diphenyl ethers. Journal of Chemical and Engineering Data 46, 239-242.

Xiao, H., Wania, F., 2003. Is vapor pressure or the octanol-air partition coefficient a better descriptor of the partitioning between gas phase and organic matter? Atmospheric Environment 37, 2867-2878. 